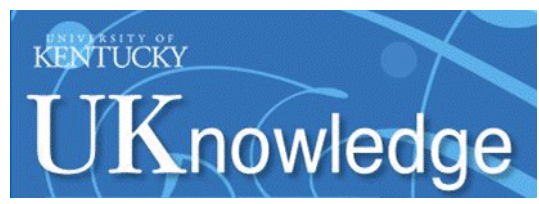

University of Kentucky

UKnowledge

Sanders-Brown Center on Aging Faculty

Publications

Aging

$10-2017$

\title{
HNE-Modified Proteins in Down Syndrome: Involvement in Development of Alzheimer Disease Neuropathology
}

\author{
Eugenio Barone \\ Sapienza University of Rome, Italy \\ Elizabeth Head \\ University of Kentucky, elizabeth.head@uky.edu \\ D. Allan Butterfield \\ University of Kentucky, david.butterfield@uky.edu \\ Marzia Perluigi \\ Sapienza University of Rome, Italy
}

Follow this and additional works at: https://uknowledge.uky.edu/sbcoa_facpub

Part of the Diseases Commons, Genetics Commons, Neurosciences Commons, and the Pathology

Commons

Right click to open a feedback form in a new tab to let us know how this document benefits you.

\section{Repository Citation}

Barone, Eugenio; Head, Elizabeth; Butterfield, D. Allan; and Perluigi, Marzia, "HNE-Modified Proteins in Down Syndrome: Involvement in Development of Alzheimer Disease Neuropathology" (2017). SandersBrown Center on Aging Faculty Publications. 121.

https://uknowledge.uky.edu/sbcoa_facpub/121

This Article is brought to you for free and open access by the Aging at UKnowledge. It has been accepted for inclusion in Sanders-Brown Center on Aging Faculty Publications by an authorized administrator of UKnowledge. For more information, please contact UKnowledge@lsv.uky.edu. 
HNE-Modified Proteins in Down Syndrome: Involvement in Development of Alzheimer Disease Neuropathology

Digital Object Identifier (DOI)

https://doi.org/10.1016/j.freeradbiomed.2016.10.508

Notes/Citation Information

Published in Free Radical Biology and Medicine, v. 111, p. 262-269.

(c) 2016 Elsevier Inc. All rights reserved.

This manuscript version is made available under the CC-BY-NC-ND 4.0 license https://creativecommons.org/licenses/by-nc-nd/4.0/.

The document available for download is the author's post-peer-review final draft of the article 


\title{
HNE-modified proteins in Down Syndrome: involvement in development of Alzheimer disease neuropathology
}

\author{
Eugenio Barone ${ }^{1}$, Elizabeth Head ${ }^{2,3}$, D Allan Butterfield ${ }^{2,4}$, and Marzia Perluigi ${ }^{1,{ }^{*}}$ \\ ${ }^{1}$ Department of Biochemical Sciences, Sapienza University of Rome, Italy \\ ${ }^{2}$ Sanders-Brown Center on Aging, University of Kentucky, Lexington, KY 40536 USA \\ ${ }^{3}$ Department of Pharmacology and Nutritional Sciences, University of Kentucky, Lexington, KY \\ 40536 USA \\ ${ }^{4}$ Department of Chemistry, University of Kentucky, Lexington, KY 40506 USA
}

\section{Abstract}

Down syndrome (DS), trisomy of chromosome 21, is the most common genetic form of intellectual disability. The neuropathology of DS involves multiple molecular mechanisms, similar to $\mathrm{AD}$, including the deposition of beta-amyloid $(\mathrm{A} \beta)$ into senile plaques and tau hyperphosphorylating in neurofibrillary tangles. Interestingly, many genes encoded by chromosome 21, in addition to being primarily linked to amyloid-beta peptide (A $\beta$ ) pathology, are responsible for increased oxidative stress (OS) conditions that also result as a consequence of reduced antioxidant system efficiency. However, redox homeostasis is disturbed by overproduction of $\mathrm{A} \beta$, which accumulates into plaques across the lifespan in $\mathrm{DS}$ as well as in $\mathrm{AD}$, thus generating a vicious cycle that amplifies OS-induced intracellular changes.

The present review describes the current literature that demonstrates the accumulation of oxidative damage in DS with a focus on the lipid peroxidation by-product, 4-hydroxy-2-nonenal (HNE). HNE reacts with proteins and can irreversibly impair their functions. We suggest that among different post-translational modifications, HNE-adducts on proteins accumulate in DS brain and play a crucial role in causing the impairment of glucose metabolism, neuronal trafficking, protein quality control and antioxidant response. We hypothesize that dysfunction of these specific pathways contribute to accelerated neurodegeneration associated with AD neuropathology.

\section{Keywords}

Down Syndrome; Alzheimer Disease; 4-hydroxy-2-nonenal; redox proteomics; protein oxidation; lipid peroxidation

*Corresponding authors: Marzia Perluigi, PhD, Department of Biochemical Sciences, Sapienza University of Rome, P.le Aldo Moro, 5 00185 Rome (IT), Phone: +39 0649910885, Fax: +39 064440062, marzia.perluigi@ uniroma1.it. 


\section{Down Syndrome neuropathology}

Down syndrome (DS) is a genetic disorder that results from the triplication of the entire portion or part of chromosome 21 (Chr21) and is considered the major genetic cause of intellectual disability. DS occurs in 1 every 800/1000 live births and presents several pathological phenotypes such as craniofacial abnormalities, small brain size, accelerated aging, cardiac defects and cognitive decline. The "gene dosage hypothesis" states that the increased dosage of Chr21 genes is the direct cause of the phenotypical alterations of DS [1-3]. However, the presence of trisomic genes also affects the expression of disomic genes, which, in turn, may gain aberrant expression and contribute to some clinical manifestations [3]. In this deregulated scenario, the effects caused by some dosage-sensitive genes are amplified and result in heterogeneous phenotypic traits according to the "number and dose" of genes involved [4]. Life expectancy in the DS population is shorter compared with nonDS individuals, but improvements in medical care and drug treatments have significantly contributed to ameliorate the quality of life of people with DS [5, 6]. Numerous developmental defects are associated with DS [7, 8], with brain development and intellectual disabilities being the most striking features of trisomy $21[9,10]$, and language, learning and memory may also be affected [11]. Unravelling the molecular mechanisms related to accelerated aging and neurodegeneration is one of the major challenges of research both for DS and AD.

Several studies support the link between the DS phenotype and an increased risk of development of $\mathrm{AD}$ [12]. The incidence of dementia among DS patients is $10 \%$ in the age range $35-50,55 \%$ in the age range $50-60$, and becomes $75 \%$ above the age of 60 years, but AD neuropathology is present in virtually all adults with DS older than 40 years [13]. However, there is a subset of aged DS persons who do not develop clinical signs of dementia at any age [14]. Neuropathological features of AD are the deposition of senile plaques (SPs) and neurofibrillary tangles (NFTs) together with cholinergic and serotonergic reduction [15, 16]. However, although plaques have been detected in young DS autopsy samples, some as young as in the fetus, it is only in late middle age that people with DS develop AD pathology.

\section{Increased oxidative stress in DS contributes to development of Alzheimer Disease neuropathology}

Several studies demonstrate that oxidative stress (OS) is involved in the development of multiple DS phenotypes (reviewed in [17]). OS represents an imbalance between the production of ROS and the efficiency of antioxidant systems - antioxidant compounds and antioxidant enzymes - to detoxify the reactive intermediates or to repair the oxidative damage [18, 19]. High levels of OS-induced by-products have been detected in brain tissue from DS $[19,20]$. Intriguingly, the causes of increased OS in DS may be searched by mapping $\mathrm{Chr} 21$, where a number of genes, directly or indirectly, promote free radical production and alter redox homeostasis of neuronal cells. Among candidate genes, the overexpression of SOD1 and APP are considered to be the leading causes of OS (Figure 1). 
SOD-1 is one of the major enzymes involved in the antioxidant defense and catalyzes the dismutation of $\mathrm{O}_{2}{ }^{--}$to molecular oxygen and $\mathrm{H}_{2} \mathrm{O}_{2}$, which in turn is metabolized by catalase (CAT) and by glutathione peroxidase (GPX) to water [21]. However, considering that brain levels of CAT and GPX are generally lower in the brain compared with other tissues, triplication of SOD-1 in DS brain results in an imbalance in the ratio of SOD-1 to CAT and GPX, thus leading to the accumulation of $\mathrm{H}_{2} \mathrm{O}_{2}$ [22]. Interestingly, this condition - altered SOD-1/GPX activity ratio - is not restricted to the brain but occurs also in all DS tissues [23]. The expression levels of SOD-1 were found to be around 50\% higher in different DS cells and tissues, such as erythrocytes, lymphocytes and fibroblasts compared with euploid control cells. SOD-1, SOD-1/GPX or the SOD-1/(GPX + CAT) activity ratios were increased in erythrocytes from people with DS, either children or adults. Findings from Shin and colleagues demonstrate that transgenic mice overexpressing wild-type human SOD1 (Tg-SOD1) displayed mitochondrial swelling, vacuolization, learning and memory deficits [24]. Similarly, Busciglio et al. [25] showed that DS neurons have higher ROS levels that are also associated with elevated markers of LPO. Nevertheless, proteomics results from Gulesserian et al. [26] suggest that increased OS conditions in fetal DS tissues are not exclusively caused by SOD-1 triplication but may be significantly associated with reduced activity of antioxidant enzymes, such as glutathione transferases and thioredoxin peroxidases.

Several studies also suggest that increased ROS production in DS could result as a consequence of amyloid beta-peptide (A $\beta$ ) overproduction [27-29], due to the overexpression of the amyloid precursor protein $(A P P)$ gene, encoded on Chr21. Several studies from the Butterfield group and others [30-32] indicate that A $\beta$ induces OS. OS occurs within the bilayer, where $A \beta(1-42)$ inserts as oligomers and serves as a source of ROS and initiates LPO (Figure 1) [30]. Deposition of senile plaques is observed in postmortem brain from DS individuals [33] and levels of both $A \beta(1-42)$ and $A \beta(1-40)$ in plasma are higher in DS compared with non-DS controls [34].

Interestingly, studies from Anandatheerthavarada et al. [35] also suggest that full length APP may be neurotoxic, primarily at the mitochondrial level. These authors suggest that increased APP expression causes a progressive accumulation of transmembrane-arrested APP that in turn disturbs mitochondrial integrity, which ultimately results in impairment of energy metabolism. Other studies support this evidence by showing that mice overexpressing wild type human APP develop neuropathology similar to AD, but lack significant plaque deposition in the hippocampus [36]. These findings led to the hypothesis that overexpression of APP may promote mitochondrial dysfunction in DS independent of aberrant $\mathrm{A} \beta$ deposition.

Another Chr21 gene that could play a role in exacerbating OS is the enzyme carbonyl reductase (CBR). Carbonyls are toxic metabolic intermediates that are mainly detoxified by aldehyde dehydrogenase or reduced by CBR and/or alcohol dehydrogenase to their corresponding alcohols. The finding that expression levels of these enzymes are increased in different brain regions of both DS and AD patients suggests they may be a protective response toward increased carbonyl production, i.e., increased oxidative damage [37]. However, CBR itself can be oxidatively modified as observed in the brains of people with 
mild cognitive impairment (MCI), and once irreversibly damaged it may lose functionality [38].

Another interesting aspect of trisomy 21 is the role of cystathionine beta synthase (CBS) that may possibly link OS to metabolic defects. CBS is the first enzyme involved in the transsulfuration pathway and catalyzes the condensation of homocysteine with serine to form cystathionine [39]. CBS catalyzes the condensation of serine and homocysteine to form cystathionine and water. CBS plays a critical role in linking the folate cycle and the methionine cycle and in regulating homocysteine levels [40]. In addition, CBS can also use cysteine alone or together with homocysteine to generate hydrogen sulfide, which has been shown to exert important neuromodulatory activities in the brain [41]. CBS protein levels and enzyme activity are increased in persons with DS [42]. This increase of CBS activity can lead to lower homocysteine levels, which in turn disturb the balance of one-carbon metabolism and lead to elevated, possibly toxic, levels of hydrogen sulfide. Taken together, these metabolic alterations might contribute to the cognitive decline observed in DS with age [43]. In line with this hypothesis, CBS is currently considered a risk factor for AD [44].

Additional trisomic genes that may be indirectly involved in the increased susceptibility of different cell types in DS to accumulate oxidative damage are those encoding for S100 $\beta$ and Ets-2.

$\mathrm{S} 100 \beta$, an astroglial-derived $\mathrm{Ca}^{2+}$-binding protein, acts as a neurotrophic factor on neurons and glial cells. S100 $\beta$ interacts with a variety of intracellular targets, such as microtubules, enzymes of the glycolytic pathway and with the tumor suppressor p53. S100 $\beta$ also regulates calcium homeostasis, protein phosphorylation and degradation. In the brain, $S 100 \beta$ is actively secreted from astrocytes in the extracellular medium [45] and has been shown to modulate the activity of neurons, microglia, astrocytes, monocytes, and endothelial cells. On neurons, $S 100 \beta$ triggers trophic or toxic effects, depending on its concentration. S100 $\beta$ expression levels are increased in both DS and AD astrocytes in association with neuritic plaques [46, 47]. In addition, chronic overexpression of $S 100 \beta$ contributes to increased neuronal and neuritic $\beta$ APP expression with consequent accelerated amyloid deposition, as well as abnormal growth of neurites in $\beta$-amyloid plaques, similar to observations in middleaged DS patients [46].

Ets-2 is a member of the Ets family of transcription factors that has important functions in cancer, bone development and immune responses. Experimental evidence shows that Ets-2 is upregulated by OS and it is involved in cell differentiation, maturation and signaling [48]. The overexpression of Ets-2 could play a role in the increased susceptibility of DS cells to undergo apoptosis given common pathophysiological features shared between Ets-2 overexpressing transgenic mice and individuals with DS [49]. Intriguingly, although Ets-2 overexpression is involved in neuronal apoptotic cell death it is conceivable that it may also play a role in the reduced incidence of solid tumors in people with DS [50].

Taken together, this "genetic fingerprint" suggests that DS individuals are exposed to chronic doses of free radicals from embryonic development until adult life as discussed 
below. Paradoxically, this may also result in activation of compensatory mechanisms as a consequence of increased OS burden [51].

\section{Lipid peroxidation and neurodegeneration: HNE and application of redox proteomics to Down Syndrome brain}

The central nervous system (CNS) is one of the major targets of lipid peroxidation (LPO) chain reactions. This susceptibility of the brain to LPO is because this organ consumes about $30 \%$ of inspired oxygen, contains high levels of polyunsaturated fatty acids (PUFAs), as phospholipids, and a significant concentration of redox transition metal ions. PUFAs, in the lipid bilayer of the plasma membrane, are the first site for $\mathrm{H}$-atom removal, specifically at the level of a repeating $=\mathrm{CH}-\mathrm{CH}(2)-\mathrm{CH}=$ unit, that in addition to conferring an extremely flexible structure, is chemically vulnerable. Indeed, it has been shown that the substitution of deuterium for hydrogen at oxidation-prone bisallylic sites of these essential fatty acids provides neuroprotection in a mouse model of OS and neurodegeneration [52].

The first reaction in LPO cascade is the abstraction of an $\mathrm{H}$-atom from the conjugate double bond system of the fatty acid acyl chain, which in turn activates a cascade of radical reactions. As a consequence, a variety of free radical species (ROS) are released. Altogether, ROS are highly unstable and easily react with all macromolecules such as proteins, nucleic acid and lipids. All these events are further exacerbated by the relative inability of neuronal cell to neutralize free radicals as the expression of antioxidant enzymes is generally lower in the brain compared with other tissues [53].

Oxidative breakdown of biological phospholipids occurs in most cellular membranes including mitochondria, microsomes, peroxisomes and plasma membrane. Free radical attack to PUFAs produces a wide variety of oxidation products, among which lipid hydroperoxides $(\mathrm{LOOH})$, many different aldehydes, which can be formed as secondary products during LPO, malondialdehyde (MDA), propanal, hexanal, acrolein and 4hydroxynonenal (4-HNE) [54, 55]. MDA is the most mutagenic [56] whereas 4-HNE is the most toxic [55]. In addition to these by-products, lipid hydroperoxyl radicals undergo endocyclization to produce fatty acid esters; two classes of these cyclized fatty acids are ispoprostanes and neuroprostanes [57].

Within the bilayer lipid soluble vitamins, glutathione, glutathione-S-transferases are the major scavengers towards lipid oxidants including HNE and provide the first line of defense. In addition, albumin and apolipoproteins in plasma can bind and detoxify HNE. However, cells do not possess a specific repair system against LPO as it occurs for repairing DNA damage and this may explain why moderate levels of LPO could have physiological significance for cell signaling and membrane remodeling [58].

Peroxidation of membrane lipids results in increased membrane rigidity and impairment of multiple membrane-associated functions including activity of membrane-bound enzymes (e.g., sodium pump), disturbance of membrane receptors and altered permeability to molecules [55]. In addition to damage to phospholipids, radicals also can directly attack membrane proteins and induce lipid-protein and protein-protein crosslinking, all of which 
contribute to disturb membrane integrity [59]. Taken together, disturbance of all the abovementioned functions displayed by PUFAs and its metabolites and the irreversible modifications of proteins with LPO by-products, affect neuronal homeostasis thus contributing to brain dysfunction.

The role of LPO in the pathogenesis and progression of neurodegenerative disorders has been confirmed by different studies [60,61]. These findings showed the elevation of markers of LPO in brain tissue and body fluids in several neurodegenerative diseases, including AD, Parkinson disease (PD), amyotrophic lateral sclerosis (ALS), Huntington disease (HD) and DS $[60,62]$. In particular, this review focuses on the role of LPO in the brains of people with DS and its role in the development of AD.

HNE is a key component of OS because it is produced in relatively large amounts, and it is a reactive aldehyde that acts as "second messenger" of free radicals [63]. Thus 4-HNE can act both as signaling molecule and as cytotoxic product of LPO causing chronic biological consequences, in particular by causing covalent modification of all macromolecules (Figure 1).

HNE, an $\alpha, \beta$ unsaturated electrophilic compound, is an amphiphilic compound, that can interact with both water-soluble and lipophilic environments. However, it has stronger hydrophobic nature and it is mostly associated with the membrane structures where it is formed, but it has the ability to diffuse in other cellular compartments and therefore interacts with different substrates [53]. HNE is a highly reactive compound due to the presence of three functional groups responsible of its electrophilic properties [64]. The presence of a conjugated system of a $\mathrm{C}=\mathrm{C}$ double bond and a $\mathrm{CO}$ carbonyl group provide a partial positive charge to carbon 3, that is further increased by the inductive effect of the hydroxy group at carbon 4. For these reasons the nucleophilic attack, for example, by thiol or amino groups, occurs primarily at carbon 3 and second at the carbonyl carbon 1 . Proteins are particularly susceptible to HNE-induced modification and HNE forms Michael adducts with three different side chains amino acids, namely Cys, His, and Lys, either with thiol (-SH) and amino $\left(-\mathrm{NH}_{2}\right)$ groups of these amino acids [65]. Cys residues have the highest reactivity, with Cys>His>Lys. As it occurs for many protein modifications, the degree of reactivity depends on the tertiary structure of the protein - accessibility - and therefore reactivity, of amino acid residues towards exogenous chemicals. 4-HNE adducts play a critical role in multiple cellular processes and can participate in secondary deleterious reactions (e.g., crosslinking) by promoting intramolecular or intermolecular protein/DNA crosslinking that may induce profound alteration in the biochemical properties of biomolecules, which may facilitate development of various pathological states.

Several proteins undergo HNE modification such as plasma membrane ion and nutrient transporters; receptors for growth factors and neurotransmitters; mitochondrial electron transport chain proteins; protein chaperones; proteasomal proteins; and cytoskeletal proteins $[65,66]$. The effects of this modification are wide and with diverse severity but having, as a whole, a significant effect on protein functionality. 
Moreover, the function of any given protein is finely regulated by post-translational modifications (PTMs) such as phosphorylation, acetylation, methylation, glutathionylation, ubiquitinylation among others. These modifications are generally reversible and are fundamental to regulate normal cellular functions. However, a different set of PTMs, which often lead to irreversible protein modifications, may also occur and give rise to dangerous effects. Among these types of potentially "toxic" changes, oxidative modification, such the covalent bonding to HNE, have been extensively investigated mostly in neurodegenerative diseases, conditions in which increased OS is a constant treat for protein homeostasis. Indeed, oxidation of a protein results in its impaired function and mostly the accumulation of oxidized proteins is a characteristic hallmark of degenerating neurons in AD and other neurodegenerative diseases [67].

\section{HNE-modified proteins contribute to neurodegeneration in Down Syndrome}

There is considerable literature supporting a major role for OS in DS clinical phenotypes. Direct evidence for a pro-oxidant state in people with DS includes those studies demonstrating significant increases in oxidative DNA damage (urinary 8-OHdG), LPO, and isoprostane 8,12-iso-iPF2alpha-VI in DS patients [27, 37, 71-73].

Relevant to the focus of this review, an increase of markers of LPO (TBARS) was found in the urine of young DS patients (about 5 years old in average) with respect to their age matched controls [71]. Similarly, Praticò et al. found elevated levels of the isoprostane 8,12iso-iPF2alpha-VI - a specific marker of LPO - in urine samples from young DS subjects (ranging from 1 to 15 years old) [27].

The pro-oxidant state in DS may contribute to our understanding of the mechanisms underlying several DS phenotypes. In particular, age-dependent measures of OS biomarkers in DS could provide insights into their contribution to accelerated ageing and to the other age associated, redox-related pathologies. An age-dependent analysis of redox parameters evaluated in plasma samples from DS subjects (1-57 years old) suggests that changes in redox status is strictly linked to age [74]. Indeed, Pallardo and colleagues showed a significant increase in 8-OHdG levels in DS patients up to 30 years old. Further, the GSSG:GSH ratio was significantly higher in young DS patients ( $<15$ years), while it is reduced in DS patients aged $>15$ years. Plasma levels of markers of protein oxidation including glyoxal (Glx) and methylglyoxal (MGlx) provided opposite results. Glx levels were significantly higher in young DS patients, whereas no significant difference was detected in DS patients aged $>15$ years. Suprisingly, MGlx was significantly lower in young DS subjects. Levels of antioxidants including ascorbic acid and vitamin $\mathrm{E}$ were also evaluated, showing that plasma concentrations of ascorbic acid are increased in young $(<15$ years) DS patients, but not in older patients, while the levels of vitamin E did not differ from control neither in young or older DS subjects [74]. These results, although in agreement with previous studies of an early pro-oxidant state occurring in DS [27, 71], also provide additional contributors accounting for a multi-faceted pro-oxidant state in DS patients, depending on age. The contribution of these age-associated changes may impact a number of 
phenotypic features of DS including accelerated ageing, cancer propensity in childhood, neurological and cognitive impairment and immunodeficiency.

Increased LPO levels evaluated as MDA production in plasma from DS patients (from new born to 29 years old) were also reported [75]. Interestingly, a pilot study evaluating plasma levels of HNE in DS patients (2-16 years old) also revealed a marked increase of HNE in DS with respect to their age-matched controls, thus reinforcing the hypothesis of a pro-oxidant state occurring early in DS [76].

The role of GSH in LPO and HNE formation also appears to be important. The increased GSSG/GSH ratio in young DS patients ( $<15$ years) is in agreement with observed elevation of LPO. Nevertheless, the GSSG/GSH ratio is reduced in plasma sample collected from older DS patients [74] possibly suggesting an activation of the antioxidant defense in response prolonged HNE exposure. However, this compensatory mechanism, that promotes synthesis of GSH through HNE-mediated induction of glutamate cysteine ligase (GCL) [77], is not coupled with decrease markers of LPO in DS older patients [9].

In addition, Perluigi et al. also describe changes occurring in amniotic fluid (AF), which are a more reliable index of the physiological condition of the fetus. The biochemical composition of AF, routinely used for prenatal diagnosis, is modified throughout pregnancy and its protein profile reflects both physiological and pathological changes affecting the fetus and the mother [78]. AF from DS pregnancies is characterized by increased levels of HNE, indicating that the LPO pathways were enhanced even at the fetal stage in DS [79]. Furthermore, in good agreement with previous studies an increase of GSSG/GSH ratio was found already at the level of AF [79], thus strongly support for a very early occurrence of a pro-oxidant state in DS. Indeed, it is important to note that, in contrast to adult brain, fetal DS neurons do not overexpress SOD-1, and therefore the impaired oxidative status may occur primarily as a consequence of the low levels of reducing agents and enzymes involved in the removal of ROS [80].

Based on the above results it appears that an increase of OS occurs early in the lifespan of people with DS. Whether these peripheral changes are paralleled in the brain and thus might be associated with intellectual disability has yet to be evaluated.

Studies performed in Ts65Dn mice (the most used animal model for the study of DS neurodegeneration) support the accumulation of oxidative/nitrosative damage in the brain. Although Ts65Dn mice do not present all the features associated with DS (such as congenital heart defects), they display many DS-like features, including significant performance deficits in specific behavioral tasks, motor dysfunction, craniofacial dysmorphogenesis, and age-related loss of cholinergic markers in the basal forebrain [81].

Increased LPO products such as 8,12-iso-iPF2alpha-VI are observed both in the cortex and hippocampus of very young mice (2 months) [82], whereas increased HNE levels are found in the hippocampus of both 6- and 12-months olds mice [83]. HNE levels in very young mice have yet to be reported, but the increase of other LPO products could suggest an increase of HNE as well. 
However, results collected in young mice are consistent with data on human AF and with the hypothesis that OS is a very early event occurring within fetal stage. Indeed, administration of a-tocopherol to pregnant Ts65Dn females from the day of conception throughout the pregnancy prevented the increase in LPO [83]. Furthermore, Gulesserian et al. found a significant reduction in levels of glutathione synthetase, glutathione-S-transferase and thioredoxin peroxidase-I and -II in DS fetal brain compared with controls, thus supporting an early impairment of GSH pathway which may contribute to the observed increase in LPO [26].

In addition, as proposed by Tramutola et al. the accumulation of HNE and HNE-bound proteins with age, could be dependent on the coexistent increase in OS together with the reduced turnover of damaged proteins. Autophagy, necessary for protein turnover, is inversely dependent on mTOR activity. The analysis of mTOR expression and phosphorylation in the hippocampus of Ts65Dn mice shows an aberrant activation of mTOR signaling starting at 6 months, which persists to 12 months of age supporting a genotypedependent alteration of the pathway. As a result of aberrant mTOR signaling, autophagosome formation is reduced in Ts65Dn mice compared with euploid mice at both 6 and 12 months of age, suggesting its possible involvement in an increase in oxidative damage in Ts65Dn mice [83].

Due to the difficulties of obtaining human brain samples, only a few studies have investigated the role of OS in the very early ages of DS. Busciglio and Yanker, used primary neuronal and astrocyte cultures from fetal DS cases and normal brains and demonstrated that DS neurons exhibit neurodegenerative changes starting at 7 days in culture and that these changes are associated with increased OS levels [25].

A study of the age-depenendency of oxidative/nitrosative stress in a cohort of DS brains ranging from 20 to 60 years was performed by Cenini et al. in 2012 [84]. As mentioned previously, DS adults over the age of 40 years show neuropathological hallmarks of AD, and therefore this cohort was useful to highlight changes occurring in the brain before and after the development of AD pathology. Interestingly, among the oxidative/nitrosative stress markers analyzed, DS patients ( $<40$ years) were characterized by increased total HNE levels together with increased levels of SDS- and FA-extracted $A \beta 40$ and $A \beta 42$ fractions in the frontal cortex [84]. A significant association was found between monomeric A $\beta 40$ and PC levels [84]. This observation seems quite surprising particularly due to the well-accepted role of A $\beta 42$ in promoting LPO rather than protein oxidation/nitration in AD [85]. However, as suggested by the same authors, one possible explanation of these data could be related to the amount of $A \beta 42$ and $A \beta 40$ measured in the frontal cortex, showing that the levels of $A \beta 40$ is consistently higher than $A \beta 42$ in the frontal cortex from DS individuals [84].

The oxidative protein modifications analysed in the frontal cortex of DS, before and after development of $\mathrm{AD}$, and age-matched control individuals allowed identifying specific dysfunctional proteins. Therefore, focusing on the identification of which proteins are oxidatively modified in DS may provide novel insights. Proteomics analysis is a useful approach for this type of investigation, resulting in a better understanding of which 
biological mechanisms are involved in the onset and progression of AD in DS, which may then provide useful information for clinical trials in DS.

A redox proteomics approach was used to evaluate HNE-modified proteins in the frontal cortex of DS and DS/AD brains along with their age-matched controls in order to shed light on the OS-induced altered molecular mechanisms, which characterizes DS pathology and my trigger the development of $\mathrm{AD}$ (results summarized in Table 1) [86].

By looking at the proteins identified to be HNE-modified, it appears that the majority of these proteins are involved in the regulation of (i) neuronal shape and trafficking; (ii) the proteostasis network and (iii) energy metabolism (reviewed in [67]). Intriguingly, all of these processes more or less rely on ATP consumption to occur efficiently. Mitochondrial dysfunction is an early event in the pathogenesis of neurodegenerative diseases. Reduced ATP levels, increased ROS, impaired calcium buffering and altered mitochondrial permeability are characteristic mitochondrial defects of degenerating neurons [87].

Through this analysis, Perluigi's laboratory identified increased levels of protein-bound HNE of myelin basic protein (MBP), a-internexin, dihydropyriminidase-related protein 1 and 2 (DRP-1/2) in DS and DS/AD patients. This was the first report showing the oxidation of MBP, the major structural protein component of myelin, which plays a functional role in the formation and maintenance of the myelin sheath. Interestingly, it was recently demonstrated that MBP is able to bind $\mathrm{A} \beta$ and to inhibit $\mathrm{A} \beta$ fibril formation breakdown in white matter $[15,88,89]$ thus suggesting a role in DS. Another member of the cytoskeleton network is $\alpha$ internexin, a $66-\mathrm{kDa}$ neurofilament protein involved in the morphogenesis of neurons.

Similarly, DRP-1 and -2 play a role in neuronal development and polarity, as well as in axon growth and guidance, neuronal growth cone collapse and cell migration [90]. These data therefore may suggest that the increased HNE modification of these proteins, whose expression is already altered in the fetal brain, contributes to the slow, chronic degenerative process of neuronal cells in DS brain [86, 90].

In addition, when oxidized/misfolded proteins accumulate in sufficient quantity, they are prone to form aggregates, which affect several intracellular pathways and negatively impact metabolism, protein turnover and trafficking [91-93]. Consistent with this hypothesis, SOD-1 was found to be HNE-modified in DS brain. Considering that SOD1 is overexpressed in DS and also oxidatively modified, it is conceivable that SOD1 aggregates might form and may contribute to neurotoxicity, as well as A $\beta$ fibrils. As reported, increased SOD1 aggregates are present in the brain of DS/AD patients, and strengthens the hypothesis that impairment of SOD1 physiological activity may contribute to the development of AD neuropathology in DS [86].

Considering that ROS damage induces protein aggregation, which in a vicious cycle further leads to ROS release, the ability to remove toxic aggregates is essential to avoid neurodegeneration. Preserving protein homoeostasis, or 'proteostasis' requires several parallel strategies that involve refolding, degradation or clearance of misfolded polypeptides [94]. Any condition promoting protein misfolding load may indeed result in an alteration of the proteostatis network, which is a crucial aspect of cell physiology. Thus it is essential for 
the vitality of the cell to promote a rapid and robust response to preserve/restore protein homoeostasis by the removal of misfolded/aggregated proteins. In particular, with regard to DS pathology, the maintenance of the proteostasis network could play a pivotal role not only for DS itself, but also for the transition to AD.

Redox proteomics analyses identified a number of HNE-modified proteins that are impaired in DS and DS/AD patients, which function as chaperones, or belong to the ubiquitinproteasome system or to the autophagy pathway. These proteins include GRP78, UCHL-1, HSC71 and GFAP. Therefore, alterations of these pathways predict that in degenerating neurons: (I) proteins with excess ubiquitinylation accumulate; (II) the activity of the $26 \mathrm{~S}$ proteasome is decreased; (III) the autophagic flux is reduced and (IV) consequent accumulation of aggregated/damaged proteins is favoured [86].

As mentioned above, impairment of energy metabolism is also a characteristic of DS brain. Glucose metabolism is essential for brain health and dysfunction of glucose utilization in the brain represents a key component in the development of neurodegenerative disorders [95-97]. Furthermore, epidemiological studies show that hallmarks of metabolic disorders, such as glucose intolerance and/or impairment of insulin secretion, are associated with a higher risk of developing dementia or AD [98-101].

Analyses performed by redox proteomics revealed that fructose-bisphosphate aldolase A, C (FBA A/C), malate dehydrogenase, a-enolase, glycealdehyde-3-phosphate dehydrogenase, cytochrome b-c1 complex, aconitate hydratase and pyruvate kinase isozymes M1/M2 are HNE-modified in DS and DS/AD patients [86]. These enzymes that are a structural part of the glycolytic pathway and TCA cycle and are oxidatively modified may be toxic stressors within neurons by by reducing energy production.

Reduced glucose utilization due to OS-induced impairment of glycolytic enzymes would be further associated with increased glucose levels as occurs in the early phases of AD [102]. According to recently discovered mechanisms, increased glucose levels would lead to an increase in extracellular glutamate release, thus resulting in NMDR activation and increased neuronal $\left[\mathrm{Ca}^{2+}\right]$, nNOS stimulation, and consequent increased OS/NS levels [103].

Similarly, increased glucose levels can evoke rapid changes in neuronal excitability through inhibition of $K_{A T P}$ channels, which results in increased $A \beta$ production [104]. Increased $A \beta$ levels, in turn, might mediate similar effects, amplifying this vicious cycle [103] and promoting mitochondrial damage [30].

To note, some of the above listed proteins were found to be HNE-modified in DS ( $<40$ years) or DS/AD (>40 years) autopsy cases (reviewed in [67]), whereby DRP-1 and -2, GRP78, MPB and aconitate hydratase were also significantly different between DS and $\mathrm{DS} / \mathrm{AD}$ groups, thus suggesting their potential role in the progression of DS toward AD pathology $[67,86]$.

\section{Concluding remarks}

In this review we summarized the pathophysiological role of HNE-modified proteins in DS neuropathology. When oxidant compounds target lipids, they can initiate the LPO process, a 
chain reaction that produces multiple breakdown molecules, such 4-HNE. Among several substrates, proteins are particularly susceptible to modification caused by this highly reactive aldehyde. Indeed, HNE and other oxidants cause chemical modifications of proteins, mostly irreversible, that affect both conformational and functional integrity of target substrates and lead, in the majority of cases, to their dysfunction. Identification of specific HNE-modified proteins by redox proteomics contributed to discern which cellular function is altered in DS compared with healthy controls. In detail, results from our group obtained from DS brain suggest that LPO affects energy production, neuronal trafficking, antioxidant response and the efficiency of degradative systems - proteasome and autophagy. These latter pathways are key mechanisms of vital importance for cell survival under stress conditions and provide a critical protective role. If these processes are defective, then damaged/dysfunctional proteins are not efficiently removed and may accumulate.

These findings provided insights into the molecular mechanisms that are impaired in DS, as observed either from animal or human studies, and suggest that deficits of the above mentioned pathways are hallmarks of neurodegeneration. Indeed, impairment of energy metabolism and proteostasis together with reduced antioxidant defense leaves neurons more susceptible to the accumulation of oxidative damage that culminates in cell death. These defects overlap in DS and AD degenerating neurons and may suggest therapeutic targets valuable for both diseases.

\section{References}

1. Antonarakis SE, Lyle R, Chrast R, Scott HS. Differential gene expression studies to explore the molecular pathophysiology of Down syndrome. Brain Res Brain Res Rev. 2001; 36:265-274. [PubMed: 11690624]

2. Antonarakis SE, Lyle R, Dermitzakis ET, Reymond A, Deutsch S. Chromosome 21 and down syndrome: from genomics to pathophysiology. Nat Rev Genet. 2004; 5:725-738. [PubMed: 15510164]

3. Iannello RC, Crack PJ, de Haan JB, Kola I. Oxidative stress and neural dysfunction in Down syndrome. J Neural Transm Suppl. 1999; 57:257-267. [PubMed: 10666681]

4. Shapiro BL. Down syndrome--a disruption of homeostasis. Am J Med Genet. 1983; 14:241-269. [PubMed: 6220605]

5. Roizen NJ, Patterson D. Down's syndrome. Lancet. 2003; 361:1281-1289. [PubMed: 12699967]

6. Bittles AH, Glasson EJ. Clinical, social, and ethical implications of changing life expectancy in Down syndrome. Dev Med Child Neurol. 2004; 46:282-286. [PubMed: 15077706]

7. Antonarakis SE, Epstein CJ. The challenge of Down syndrome. Trends Mol Med. 2006; 12:473479. [PubMed: 16935027]

8. Delabar JM, Aflalo-Rattenbac R, Creau N. Developmental defects in trisomy 21 and mouse models. ScientificWorldJournal. 2006; 6:1945-1964. [PubMed: 17205199]

9. Devenny DA, Krinsky-McHale SJ, Sersen G, Silverman WP. Sequence of cognitive decline in dementia in adults with Down's syndrome. J Intellect Disabil Res. 2000; 44(Pt 6):654-665. [PubMed: 11115020]

10. Devenny DA, Wegiel J, Schupf N, Jenkins E, Zigman W, Krinsky-McHale SJ, Silverman WP. Dementia of the Alzheimer's type and accelerated aging in Down syndrome. Sci Aging Knowledge Environ. 2005; 2005:dn1. [PubMed: 15814818]

11. Carlesimo GA, Marotta L, Vicari S. Long-term memory in mental retardation: evidence for a specific impairment in subjects with Down's syndrome. Neuropsychologia. 1997; 35:71-79. [PubMed: 8981379] 
12. Bush A, Beail N. Risk factors for dementia in people with down syndrome: issues in assessment and diagnosis. Am J Ment Retard. 2004; 109:83-97. [PubMed: 15000668]

13. Ghezzo A, Salvioli S, Solimando MC, Palmieri A, Chiostergi C, Scurti M, Lomartire L, Bedetti F, Cocchi G, Follo D, Pipitone E, Rovatti P, Zamberletti J, Gomiero T, Castellani G, Franceschi C. Age-related changes of adaptive and neuropsychological features in persons with Down Syndrome. PloS one. 2014; 9:e113111. [PubMed: 25419980]

14. Zigman WB, Schupf N, Sersen E, Silverman W. Prevalence of dementia in adults with and without Down syndrome. Am J Ment Retard. 1996; 100:403-412. [PubMed: 8718994]

15. Capone GT. Down syndrome: advances in molecular biology and the neurosciences. J Dev Behav Pediatr. 2001; 22:40-59. [PubMed: 11265922]

16. Krasuski JS, Alexander GE, Horwitz B, Rapoport SI, Schapiro MB. Relation of medial temporal lobe volumes to age and memory function in nondemented adults with Down's syndrome: implications for the prodromal phase of Alzheimer's disease. Am J Psychiatry. 2002; 159:74-81. [PubMed: 11772693]

17. Perluigi M, Butterfield DA. Oxidative stress and Down Syndrome: A Route toward AlzheimerLike Dementia. Curr Gerontol Geriatr Res. 2012; 2012:724904. [PubMed: 22203843]

18. Lott IT. Antioxidants in Down syndrome. Biochim Biophys Acta. 2012; 1822:657-663. [PubMed: 22206998]

19. Reynolds GP, Cutts AJ. Free radical damage in Down's syndrome brain. Biochem Soc Trans. 1993; 21:221S. [PubMed: 8359470]

20. Brooksbank BW, Martinez M, Balazs R. Altered composition of polyunsaturated fatty acyl groups in phosphoglycerides of Down's syndrome fetal brain. J Neurochem. 1985; 44:869-874. [PubMed: 3156210]

21. Benzi G, Moretti A. Are reactive oxygen species involved in Alzheimer's disease? Neurobiol Aging. 1995; 16:661-674. [PubMed: 8544918]

22. Zana M, Janka Z, Kalman J. Oxidative stress: a bridge between Down's syndrome and Alzheimer's disease. Neurobiol Aging. 2007; 28:648-676. [PubMed: 16624449]

23. de Haan JB, Cristiano F, Iannello RC, Kola I. Cu/Zn-superoxide dismutase and glutathione peroxidase during aging. Biochem Mol Biol Int. 1995; 35:1281-1297. [PubMed: 7492966]

24. Shin JH, London J, Le Pecheur M, Hoger H, Pollak D, Lubec G. Aberrant neuronal and mitochondrial proteins in hippocampus of transgenic mice overexpressing human $\mathrm{Cu} / \mathrm{Zn}$ superoxide dismutase 1. Free Radic Biol Med. 2004; 37:643-653. [PubMed: 15288122]

25. Busciglio J, Yankner BA. Apoptosis and increased generation of reactive oxygen species in Down's syndrome neurons in vitro. Nature. 1995; 378:776-779. [PubMed: 8524410]

26. Gulesserian T, Engidawork E, Fountoulakis M, Lubec G. Antioxidant proteins in fetal brain: superoxide dismutase-1 (SOD-1) protein is not overexpressed in fetal Down syndrome. J Neural Transm Suppl. 2001:71-84. [PubMed: 11771762]

27. Pratico D, Iuliano L, Amerio G, Tang LX, Rokach J, Sabatino G, Violi F. Down's syndrome is associated with increased 8,12-iso-iPF2alpha-VI levels: evidence for enhanced lipid peroxidation in vivo. Ann Neurol. 2000; 48:795-798. [PubMed: 11079545]

28. Butterfield DA, Drake J, Pocernich C, Castegna A. Evidence of oxidative damage in Alzheimer's disease brain: central role for amyloid beta-peptide. Trends Mol Med. 2001; 7:548-554. [PubMed: 11733217]

29. Butterfield DA, Galvan V, Lange MB, Tang H, Sowell RA, Spilman P, Fombonne J, Gorostiza O, Zhang J, Sultana R, Bredesen DE. In vivo oxidative stress in brain of Alzheimer disease transgenic mice: Requirement for methionine 35 in amyloid beta-peptide of APP. Free Radic Biol Med. 2010; 48:136-144. [PubMed: 19854267]

30. Butterfield DA, Swomley AM, Sultana R. Amyloid beta-peptide (1-42)-induced oxidative stress in Alzheimer disease: importance in disease pathogenesis and progression. Antioxidants \& redox signaling. 2013; 19:823-835. [PubMed: 23249141]

31. Butterfield DA. Amyloid beta-peptide (1-42)-induced oxidative stress and neurotoxicity: implications for neurodegeneration in Alzheimer's disease brain. A review. Free radical research. 2002; 36:1307-1313. [PubMed: 12607822] 
32. Mao P, Reddy PH. Aging and amyloid beta-induced oxidative DNA damage and mitochondrial dysfunction in Alzheimer's disease: implications for early intervention and therapeutics. Biochim Biophys Acta. 2011; 1812:1359-1370. [PubMed: 21871956]

33. Head E, Lott IT. Down syndrome and beta-amyloid deposition. Curr Opin Neurol. 2004; 17:95100. [PubMed: 15021233]

34. Mehta PD, Capone G, Jewell A, Freedland RL. Increased amyloid beta protein levels in children and adolescents with Down syndrome. J Neurol Sci. 2007; 254:22-27. [PubMed: 17275850]

35. Anandatheerthavarada HK, Biswas G, Robin MA, Avadhani NG. Mitochondrial targeting and a novel transmembrane arrest of Alzheimer's amyloid precursor protein impairs mitochondrial function in neuronal cells. J Cell Biol. 2003; 161:41-54. [PubMed: 12695498]

36. Simon AM, Schiapparelli L, Salazar-Colocho P, Cuadrado-Tejedor M, Escribano L, Lopez de Maturana R, Del Rio J, Perez-Mediavilla A, Frechilla D. Overexpression of wild-type human APP in mice causes cognitive deficits and pathological features unrelated to Abeta levels. Neurobiol Dis. 2009; 33:369-378. [PubMed: 19101630]

37. Balcz B, Kirchner L, Cairns N, Fountoulakis M, Lubec G. Increased brain protein levels of carbonyl reductase and alcohol dehydrogenase in Down syndrome and Alzheimer's disease. J Neural Transm Suppl. 2001:193-201. [PubMed: 11771743]

38. Reed T, Perluigi M, Sultana R, Pierce WM, Klein JB, Turner DM, Coccia R, Markesbery WR, Butterfield DA. Redox proteomic identification of 4-hydroxy-2-nonenal-modified brain proteins in amnestic mild cognitive impairment: insight into the role of lipid peroxidation in the progression and pathogenesis of Alzheimer's disease. Neurobiol Dis. 2008; 30:107-120. [PubMed: 18325775]

39. Munke M, Kraus JP, Ohura T, Francke U. The gene for cystathionine beta-synthase (CBS) maps to the subtelomeric region on human chromosome $21 \mathrm{q}$ and to proximal mouse chromosome 17 . Am $\mathrm{J}$ Hum Genet. 1988; 42:550-559. [PubMed: 2894761]

40. Hensley K, Venkova K, Christov A. Emerging biological importance of central nervous system lanthionines. Molecules. 2010; 15:5581-5594. [PubMed: 20714314]

41. Whiteman M, Armstrong JS, Chu SH, Jia-Ling S, Wong BS, Cheung NS, Halliwell B, Moore PK. The novel neuromodulator hydrogen sulfide: an endogenous peroxynitrite 'scavenger'? J Neurochem. 2004; 90:765-768. [PubMed: 15255956]

42. Ichinohe A, Kanaumi T, Takashima S, Enokido Y, Nagai Y, Kimura H. Cystathionine beta-synthase is enriched in the brains of Down's patients. Biochem Biophys Res Commun. 2005; 338:15471550. [PubMed: 16274669]

43. Kamoun P, Belardinelli MC, Chabli A, Lallouchi K, Chadefaux-Vekemans B. Endogenous hydrogen sulfide overproduction in Down syndrome. Am J Med Genet A. 2003; 116A:310-311. [PubMed: 12503113]

44. Beyer K, Lao JI, Carrato C, Rodriguez-Vila A, Latorre P, Mataro M, Llopis MA, Mate JL, Ariza A. Cystathionine beta synthase as a risk factor for Alzheimer disease. Curr Alzheimer Res. 2004; 1:127-133. [PubMed: 15975077]

45. Griffin WS, Sheng JG, McKenzie JE, Royston MC, Gentleman SM, Brumback RA, Cork LC, Del Bigio MR, Roberts GW, Mrak RE. Life-long overexpression of S100beta in Down's syndrome: implications for Alzheimer pathogenesis. Neurobiol Aging. 1998; 19:401-405. [PubMed: 9880042]

46. Royston MC, McKenzie JE, Gentleman SM, Sheng JG, Mann DM, Griffin WS, Mrak RE. Overexpression of s100beta in Down's syndrome: correlation with patient age and with betaamyloid deposition. Neuropathol Appl Neurobiol. 1999; 25:387-393. [PubMed: 10564528]

47. Van Eldik LJ, Griffin WS. S100 beta expression in Alzheimer's disease: relation to neuropathology in brain regions. Biochim Biophys Acta. 1994; 1223:398-403. [PubMed: 7918676]

48. Lott IT, Head E, Doran E, Busciglio J. Beta-amyloid, oxidative stress and down syndrome. Curr Alzheimer Res. 2006; 3:521-528. [PubMed: 17168651]

49. Wolvetang EJ, Wilson TJ, Sanij E, Busciglio J, Hatzistavrou T, Seth A, Hertzog PJ, Kola I. ETS2 overexpression in transgenic models and in Down syndrome predisposes to apoptosis via the p53 pathway. Hum Mol Genet. 2003; 12:247-255. [PubMed: 12554679] 
50. Sanij E, Hatzistavrou T, Hertzog P, Kola I, Wolvetang EJ. Ets-2 is induced by oxidative stress and sensitizes cells to $\mathrm{H}(2) \mathrm{O}(2)$-induced apoptosis: implications for Down's syndrome. Biochem Biophys Res Commun. 2001; 287:1003-1008. [PubMed: 11573964]

51. Head E, Lott IT, Patterson D, Doran E, Haier RJ. Possible compensatory events in adult Down syndrome brain prior to the development of Alzheimer disease neuropathology: targets for nonpharmacological intervention. Journal of Alzheimer's disease : JAD. 2007; 11:61-76. [PubMed: 17361036]

52. Shchepinov MS, Chou VP, Pollock E, Langston JW, Cantor CR, Molinari RJ, Manning-Bog AB. Isotopic reinforcement of essential polyunsaturated fatty acids diminishes nigrostriatal degeneration in a mouse model of Parkinson's disease. Toxicology letters. 2011; 207:97-103. [PubMed: 21906664]

53. Butterfield, DA., Stadman, ER. Protein oxidation processes in aging brain. In: Paula, ST., Bittar, EE., editors. Advances in Cell Aging and Gerontology. 1997. p. 161-191.

54. Esterbauer H, Schaur RJ, Zollner H. Chemistry and biochemistry of 4-hydroxynonenal, malonaldehyde and related aldehydes. Free Radic Biol Med. 1991; 11:81-128. [PubMed: 1937131]

55. Ayala A, Munoz MF, Arguelles S. Lipid peroxidation: production, metabolism, and signaling mechanisms of malondialdehyde and 4-hydroxy-2-nonenal. Oxidative medicine and cellular longevity. 2014; 2014:360438. [PubMed: 24999379]

56. Niedernhofer LJ, Daniels JS, Rouzer CA, Greene RE, Marnett LJ. Malondialdehyde, a product of lipid peroxidation, is mutagenic in human cells. The Journal of biological chemistry. 2003; 278:31426-31433. [PubMed: 12775726]

57. Miller E, Morel A, Saso L, Saluk J. Isoprostanes and neuroprostanes as biomarkers of oxidative stress in neurodegenerative diseases. Oxidative medicine and cellular longevity. 2014; 2014:572491. [PubMed: 24868314]

58. Radak Z, Zhao Z, Goto S, Koltai E. Age-associated neurodegeneration and oxidative damage to lipids, proteins and DNA. Mol Aspects Med. 2011; 32:305-315. [PubMed: 22020115]

59. Rahman K. Studies on free radicals, antioxidants, and co-factors. Clinical interventions in aging. 2007; 2:219-236. [PubMed: 18044138]

60. Shoeb M, Ansari NH, Srivastava SK, Ramana KV. 4-Hydroxynonenal in the pathogenesis and progression of human diseases. Current medicinal chemistry. 2014; 21:230-237. [PubMed: 23848536]

61. Perluigi M, Coccia R, Butterfield DA. 4-Hydroxy-2-nonenal, a reactive product of lipid peroxidation, and neurodegenerative diseases: a toxic combination illuminated by redox proteomics studies. Antioxidants \& redox signaling. 2012; 17:1590-1609. [PubMed: 22114878]

62. Butterfield DA, Bader Lange ML, Sultana R. Involvements of the lipid peroxidation product, HNE, in the pathogenesis and progression of Alzheimer's disease. Biochim Biophys Acta. 2010; 1801:924-929. [PubMed: 20176130]

63. Zarkovic N, Zarkovic K, Schaur RJ, Stolc S, Schlag G, Redl H, Waeg G, Borovic S, Loncaric I, Juric G, Hlavka V. 4-Hydroxynonenal as a second messenger of free radicals and growth modifying factor. Life Sci. 1999; 65:1901-1904. [PubMed: 10576434]

64. Higdon A, Diers AR, Oh JY, Landar A, Darley-Usmar VM. Cell signalling by reactive lipid species: new concepts and molecular mechanisms. Biochem J. 2012; 442:453-464. [PubMed: 22364280]

65. Sultana R, Perluigi M, Allan Butterfield D. Lipid peroxidation triggers neurodegeneration: a redox proteomics view into the Alzheimer disease brain. Free Radic Biol Med. 2013; 62:157-169. [PubMed: 23044265]

66. Pizzimenti S, Ciamporcero E, Daga M, Pettazzoni P, Arcaro A, Cetrangolo G, Minelli R, Dianzani C, Lepore A, Gentile F, Barrera G. Interaction of aldehydes derived from lipid peroxidation and membrane proteins. Frontiers in physiology. 2013; 4:242. [PubMed: 24027536]

67. Butterfield DA, Di Domenico F, Swomley AM, Head E, Perluigi M. Redox proteomics analysis to decipher the neurobiology of Alzheimer-like neurodegeneration: overlaps in Down's syndrome and Alzheimer's disease brain. Biochem J. 2014; 463:177-189. [PubMed: 25242166] 
68. Chandramouli K, Qian PY. Proteomics: challenges, techniques and possibilities to overcome biological sample complexity. Human genomics and proteomics : HGP. 2009; 2009

69. Butterfield DA, Perluigi M, Reed T, Muharib T, Hughes CP, Robinson RA, Sultana R. Redox proteomics in selected neurodegenerative disorders: from its infancy to future applications. Antioxidants \& redox signaling. 2012; 17:1610-1655. [PubMed: 22115501]

70. Butterfield DA, Gu L, Di Domenico F, Robinson RA. Mass spectrometry and redox proteomics: applications in disease. Mass spectrometry reviews. 2014; 33:277-301. [PubMed: 24930952]

71. Jovanovic SV, Clements D, MacLeod K. Biomarkers of oxidative stress are significantly elevated in Down syndrome. Free Radic Biol Med. 1998; 25:1044-1048. [PubMed: 9870557]

72. Zitnanova I, Korytar P, Aruoma OI, Sustrova M, Garaiova I, Muchova J, Kalnovicova T, Pueschel S, Durackova Z. Uric acid and allantoin levels in Down syndrome: antioxidant and oxidative stress mechanisms? Clin Chim Acta. 2004; 341:139-146. [PubMed: 14967170]

73. Nagyova A, Sustrova M, Raslova K. Serum lipid resistance to oxidation and uric acid levels in subjects with Down's syndrome. Physiol Res. 2000; 49:227-231. [PubMed: 10984088]

74. Pallardo FV, Degan P, d'Ischia M, Kelly FJ, Zatterale A, Calzone R, Castello G, FernandezDelgado R, Dunster C, Lloret A, Manini P, Pisanti MA, Vuttariello E, Pagano G. Multiple evidence for an early age pro-oxidant state in Down Syndrome patients. Biogerontology. 2006; 7:211-220. [PubMed: 16612664]

75. Casado A, Lopez-Fernandez ME, Ruiz R. Lipid peroxidation in Down syndrome caused by regular trisomy 21, trisomy 21 by Robertsonian translocation and mosaic trisomy 21 . Clin Chem Lab Med. 2007; 45:59-62. [PubMed: 17243916]

76. Briuglia, S., Cuppari, C., Comito, D., Russo, B., Caruso, R., Loddo, I., Melcarne, L., Calabrò, GE., Salpietro, DV., Gallizzi, R. Markers di stress ossidativo in bambini con Sindrome di Down. 2009. http://www.geneticapediatrica.it/archivi/2009/archivio1/_index.php?id=5

77. Forman HJ, Dickinson DA, Iles KE. HNE--signaling pathways leading to its elimination. Mol Aspects Med. 2003; 24:189-194. [PubMed: 12892996]

78. Kolialexi A, Vrettou C, Traeger-Synodinos J, Burgemeister R, Papantoniou N, Kanavakis E, Antsaklis A, Mavrou A. Noninvasive prenatal diagnosis of beta-thalassaemia using individual fetal erythroblasts isolated from maternal blood after enrichment. Prenat Diagn. 2007; 27:1228-1232. [PubMed: 17987605]

79. Perluigi M, di Domenico F, Fiorini A, Cocciolo A, Giorgi A, Foppoli C, Butterfield DA, Giorlandino M, Giorlandino C, Schinina ME, Coccia R. oxidative stress occurs early in Down syndrome pregnancy: A redox proteomics analysis of amniotic fluid. Proteomics Clin Appl. 2011; 5:167-178. [PubMed: 21360684]

80. Gulesserian T, Seidl R, Hardmeier R, Cairns N, Lubec G. Superoxide dismutase SOD1, encoded on chromosome 21, but not SOD2 is overexpressed in brains of patients with Down syndrome. J Investig Med. 2001; 49:41-46.

81. Davisson MT, Schmidt C, Reeves RH, Irving NG, Akeson EC, Harris BS, Bronson RT. Segmental trisomy as a mouse model for Down syndrome. Prog Clin Biol Res. 1993; 384:117-133. [PubMed: 8115398]

82. Shichiri M, Yoshida Y, Ishida N, Hagihara Y, Iwahashi H, Tamai H, Niki E. alpha-Tocopherol suppresses lipid peroxidation and behavioral and cognitive impairments in the Ts65Dn mouse model of Down syndrome. Free Radic Biol Med. 2011; 50:1801-1811. [PubMed: 21447382]

83. Tramutola A, Lanzillotta C, Arena A, Barone E, Perluigi M, Di Domenico F. Increased Mammalian Target of Rapamycin Signaling Contributes to the Accumulation of Protein Oxidative Damage in a Mouse Model of Down's Syndrome. Neurodegener Dis. 2016; 16:62-68. [PubMed: 26606243]

84. Cenini G, Dowling AL, Beckett TL, Barone E, Mancuso C, Murphy MP, Levine H 3rd, Lott IT, Schmitt FA, Butterfield DA, Head E. Association between frontal cortex oxidative damage and beta-amyloid as a function of age in Down syndrome. Biochim Biophys Acta. 2012; 1822:130 138. [PubMed: 22009041]

85. Swomley AM, Forster S, Keeney JT, Triplett J, Zhang Z, Sultana R, Butterfield DA. Abeta, oxidative stress in Alzheimer disease: evidence based on proteomics studies. Biochim Biophys Acta. 2014; 1842:1248-1257. [PubMed: 24120836] 
86. Di Domenico F, Pupo G, Tramutola A, Giorgi A, Schinina ME, Coccia R, Head E, Butterfield DA, Perluigi M. Redox proteomics analysis of HNE-modified proteins in Down syndrome brain: clues for understanding the development of Alzheimer disease. Free Radic Biol Med. 2014; 71:270-280. [PubMed: 24675226]

87. Lin MT, Beal MF. Mitochondrial dysfunction and oxidative stress in neurodegenerative diseases. Nature. 2006; 443:787-795. [PubMed: 17051205]

88. Epstein CJ. Epilogue: toward the twenty-first century with Down syndrome--a personal view of how far we have come and of how far we can reasonably expect to go. Prog Clin Biol Res. 1995; 393:241-246. [PubMed: 8545454]

89. Holtzman DM, Kilbridge J, Chen KS, Rabin J, Luche R, Carlson E, Epstein CJ, Mobley WC. Preliminary characterization of the central nervous system in partial trisomy 16 mice. Prog Clin Biol Res. 1995; 393:227-240. [PubMed: 8545453]

90. Weitzdoerfer R, Fountoulakis M, Lubec G. Aberrant expression of dihydropyrimidinase related proteins-2,-3 and -4 in fetal Down syndrome brain. J Neural Transm Suppl. 2001:95-107. [PubMed: 11771764]

91. Dunlop RA, Brunk UT, Rodgers KJ. Oxidized proteins: mechanisms of removal and consequences of accumulation. IUBMB Life. 2009; 61:522-527. [PubMed: 19391165]

92. Perluigi M, Sultana R, Cenini G, Di Domenico F, Memo M, Pierce WM, Coccia R, Butterfield DA. Redox proteomics identification of 4-hydroxynonenal-modified brain proteins in Alzheimer's disease: Role of lipid peroxidation in Alzheimer's disease pathogenesis. Proteomics Clin Appl. 2009; 3:682-693. [PubMed: 20333275]

93. Reed TT, Pierce WM, Markesbery WR, Butterfield DA. Proteomic identification of HNE-bound proteins in early Alzheimer disease: Insights into the role of lipid peroxidation in the progression of AD. Brain research. 2009; 1274:66-76. [PubMed: 19374891]

94. Chen Q, Chen B. Editorial: efficient strategies for signalling pathway mining. Curr Protein Pept Sci. 2011; 12:589-590. [PubMed: 22181021]

95. Mergenthaler P, Lindauer U, Dienel GA, Meisel A. Sugar for the brain: the role of glucose in physiological and pathological brain function. Trends Neurosci. 2013; 36:587-597. [PubMed: 23968694]

96. Duarte AI, Candeias E, Correia SC, Santos RX, Carvalho C, Cardoso S, Placido A, Santos MS, Oliveira CR, Moreira PI. Crosstalk between diabetes and brain: Glucagon-like peptide-1 mimetics as a promising therapy against neurodegeneration. Bba-Mol Basis Dis. 2013; 1832:527-541.

97. Dunn L, Allen GFG, Mamais A, Ling HL, Li A, Duberley KE, Hargreaves IP, Pope S, Holton JL, Lees A, Heales SJ, Bandopadhyay R. Dysregulation of glucose metabolism is an early event in sporadic Parkinson's disease. Neurobiology of Aging. 2014; 35:1111-1115. [PubMed: 24300239]

98. De Felice FG. Alzheimer's disease and insulin resistance: translating basic science into clinical applications. The Journal of clinical investigation. 2013; 123:531-539. [PubMed: 23485579]

99. Ott A, Stolk RP, van Harskamp F, Pols HA, Hofman A, Breteler MM. Diabetes mellitus and the risk of dementia: The Rotterdam Study. Neurology. 1999; 53:1937-1942. [PubMed: 10599761]

100. Crane PK, Walker R, Larson EB. Glucose levels and risk of dementia. The New England journal of medicine. 2013; 369:1863-1864.

101. Willette AA, Bendlin BB, Starks EJ, Birdsill AC, Johnson SC, Christian BT, Okonkwo OC, La Rue A, Hermann BP, Koscik RL, Jonaitis EM, Sager MA, Asthana S. Association of Insulin Resistance With Cerebral Glucose Uptake in Late Middle-Aged Adults at Risk for Alzheimer Disease. JAMA neurology. 2015

102. Xu J, Begley P, Church SJ, Patassini S, McHarg S, Kureishy N, Hollywood KA, Waldvogel HJ, Liu H, Zhang S, Lin W, Herholz K, Turner C, Synek BJ, Curtis MA, Rivers-Auty J, Lawrence CB, Kellett KA, Hooper NM, Vardy ER, Wu D, Unwin RD, Faull RL, Dowsey AW, Cooper GJ. Elevation of brain glucose and polyol-pathway intermediates with accompanying brain-copper deficiency in patients with Alzheimer's disease: metabolic basis for dementia. Scientific reports. 2016; 6:27524. [PubMed: 27276998]

103. Akhtar MW, Sanz-Blasco S, Dolatabadi N, Parker J, Chon K, Lee MS, Soussou W, McKercher SR, Ambasudhan R, Nakamura T, Lipton SA. Elevated glucose and oligomeric beta-amyloid 
disrupt synapses via a common pathway of aberrant protein S-nitrosylation. Nature communications. 2016; 7:10242.

104. Macauley SL, Stanley M, Caesar EE, Yamada SA, Raichle ME, Perez R, Mahan TE, Sutphen CL, Holtzman DM. Hyperglycemia modulates extracellular amyloid-beta concentrations and neuronal activity in vivo. The Journal of clinical investigation. 2015; 125:2463-2467. [PubMed: 25938784] 


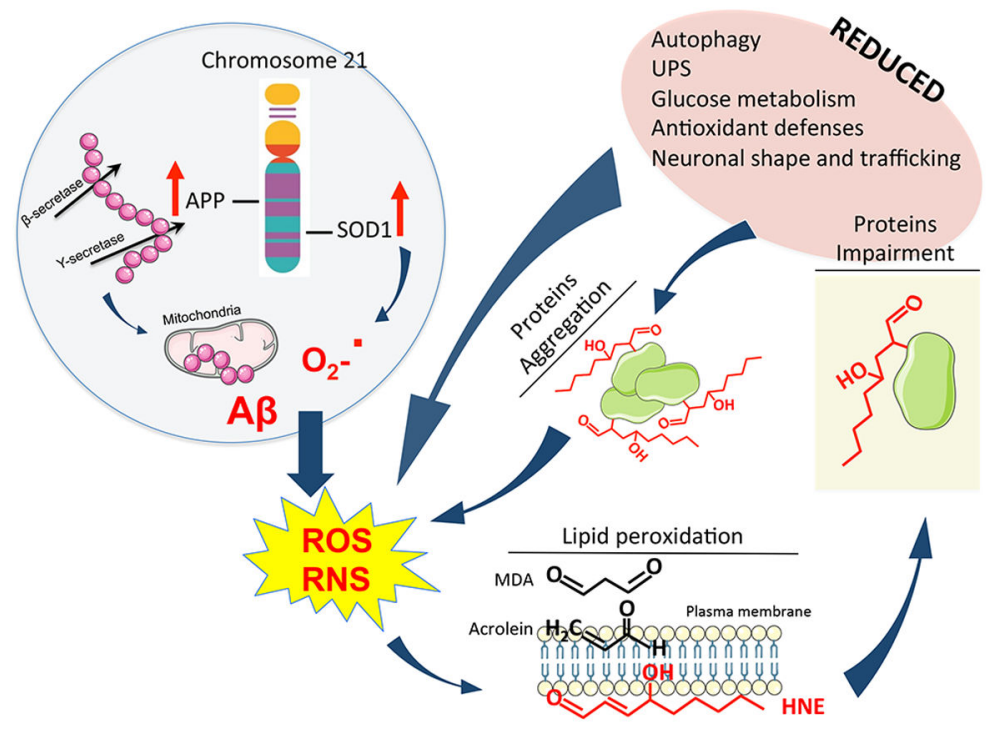

Figure 1. Increased lipid peroxidation product HNE leads to neurotoxic effects in Down syndrome brain

Trisomy of chromosome 21 in Down syndrome (DS) brain is associated with the overexpression of a number of proteins among which are amyloid precursor protein (APP) and superoxide dismutase 1 (SOD1). Overexpression of APP and SOD1 is considered to be associated with an increased production of amyloid beta-peptide $(\mathrm{A} \beta)$ and superoxide anion $\left(\mathrm{O}_{2}^{-\cdot}\right)$, respectively. Furthermore, increased $\mathrm{A} \beta$ levels are able to promote mitochondrial damage and thus to sustain a further elevation of $\mathrm{O}_{2}^{-\cdot}$ levels. These events are associated with an increase of both reactive oxygen species (ROS) and reactive nitrogen species (RNS), known to promote proteins and lipids peroxidation. Among the LPO products, 4-hydroxy-2nonenal (HNE) is known to bind proteins, thus modifying protein structure and promoting proteins impairment. Proteins found to be HNE-modified in DS brain are associated with reduced: (I) autophagy; (II) unfolded protein response (UPS); (III) glucose metabolism; (IV) antioxidant defense and (V) neuronal trafficking. All these events contribute to sustain a further increase of ROS/RNS, thus amplifying a vicious cycle. In addition, HNE modifications would promote proteins aggregation, which, because the observed defects in autophagy and UPS, are less cleared from neurons. Increased protein aggregation like in the case of $A \beta$ and SOD1, also represent an additional stimulus sustaining ROS/RNS production. 
Table 1

Redox proteomics results about HNE-modified proteins in DS: overlaps with AD or MCI

\begin{tabular}{|c|c|c|c|c|}
\hline Proteins & $\begin{array}{c}\text { DS } \\
(\text { Frontal Cortex) }\end{array}$ & $\begin{array}{c}\text { AD } \\
\text { (Hippocampus, } \\
\begin{array}{c}\text { inferior parietal } \\
\text { lobule) }\end{array}\end{array}$ & $\begin{array}{c}\text { MCI } \\
\text { (Hippocampus, } \\
\begin{array}{c}\text { inferior parietal } \\
\text { lobule) }\end{array}\end{array}$ & Function \\
\hline Superoxide dismutase $(\mathrm{Cu}, \mathrm{Zn})$ & $\checkmark$ & & & \\
\hline Peroxiredoxin-2 & $\checkmark$ & & & \\
\hline Myelin basic protein & $\checkmark$ & & & \\
\hline $\begin{array}{l}\text { Cytochrome } b-c_{1} \text { complex subunit Rieske, } \\
\text { mitochondrial }\end{array}$ & $\checkmark$ & & & \\
\hline Ubiquitin carboxyl-terminal hydrolase isozyme L1 & $\checkmark$ & & & \\
\hline Malate dehydrogenase, cytoplasmic & $\checkmark$ & & $\checkmark$ & Energy metabolism \\
\hline Glyceraldehyde-3-phosphate dehydrogenase & $\checkmark$ & & & \\
\hline Fructose-bisphosphate aldolase A & $\checkmark$ & & & \\
\hline Fructose-bisphosphate aldolase $\mathrm{C}$ & $\checkmark$ & & & \\
\hline a-Enolase & $\checkmark$ & $\checkmark$ & $\checkmark$ & Energy metabolism \\
\hline Glial fibrillary acidic protein & $\checkmark$ & & & \\
\hline Dna J homolog subfamily B member 12 & $\checkmark$ & & & \\
\hline a-Internexin & $\checkmark$ & & & \\
\hline T-complex protein 1 subunit $\beta$ & $\checkmark$ & & & \\
\hline Syntaxin-binding protein 1 & $\checkmark$ & & & \\
\hline Glutamate dehydrogenase 1 , mitochondrial & $\checkmark$ & & & \\
\hline Pyruvate kinase isozymes M1/M2 & $\checkmark$ & & $\checkmark$ & Energy metabolism \\
\hline Aconitate hydratase, mitochondrial & $\checkmark$ & & & \\
\hline Dihydropyrimidinase-related protein 1 & $\checkmark$ & & & \\
\hline Dihydropyrimidinase-related protein 2 & $\checkmark$ & $\checkmark$ & $\checkmark$ & Cell structure \\
\hline Heat shock cognate $71-\mathrm{kDa}$ protein & $\checkmark$ & & & \\
\hline 78-kDa glucose-regulated protein & $\checkmark$ & & & \\
\hline Endoplasmin & $\checkmark$ & & & \\
\hline Neurofilament medium polypeptide & $\checkmark$ & & & \\
\hline
\end{tabular}

Proteins in boldface appear in more than one group. Reference papers are: for DS group [86], for AD group [92] and for MCI group [93] 